\title{
ORIGINAL ARTICLE mGluR2/3 mechanisms in primate dorsolateral prefrontal cortex: evidence for both presynaptic and postsynaptic actions
}

\author{
LE Jin, M Wang, S-T Yang, Y Yang, VC Galvin, TC Lightbourne, D Ottenheimer, Q Zhong, J Stein, A Raja, CD Paspalas and AFT Arnsten
}

Cognitive deficits in psychiatric and age-related disorders generally involve dysfunction of the dorsolateral prefrontal cortex (dIPFC), but there are few treatments for these debilitating symptoms. Group II metabotropic glutamate receptors (mGluR2/3), which couple to $\mathrm{Gi} / \mathrm{Go}$, have been a focus of therapeutics based on rodent research, where mGluR2/3 have been shown to reduce axonal glutamate release and increase glial glutamate uptake. However, this strategy has had mixed results in patients, and understanding mGluR2/3 mechanisms in primates will help guide therapeutic interventions. The current study examined mGluR2/3 localization and actions in the primate dIPFC layer III circuits underlying working memory, where the persistent firing of 'Delay cells' is mediated by $\mathrm{N}$-methyl-D-aspartate receptors and weakened by CAMP-PKA-potassium channel signaling in dendritic spines. Immunoelectron microscopy identified postsynaptic mGluR2/3 in the spines, in addition to the traditional presynaptic and astrocytic locations. In vivo iontophoretic application of the mGluR2/3 agonists $(2 R, 4 R)$-APDC or LY379268 onto dIPFC Delay cells produced an inverted-U effect on working memory representation, with enhanced neuronal firing following low doses of mGluR2/3 agonists. The enhancing effects were reversed by an mGluR2/3 antagonist or by activating CAMP signaling, consistent with mGluR2/3 inhibiting postsynaptic CAMP signaling in spines. Systemic administration of these agonists to monkeys performing a working memory task also produced an inverted-U dose-response, where low doses improved performance but higher doses, similar to clinical trials, had mixed effects. Our data suggest that low doses of mGluR2/3 stimulation may have therapeutic effects through unexpected postsynaptic actions in dIPFC, strengthening synaptic connections and improving cognitive function.

Molecular Psychiatry (2017) 22, 1615-1625; doi:10.1038/mp.2016.129; published online 9 August 2016

\section{INTRODUCTION}

There is a great need for new treatments for cognitive disorders, and group II metabotropic glutamate receptors (mGluR2/3) have become a focus for potential therapeutics. ${ }^{1,2}$ Although initial trials with mGluR2/3 agonists have had mixed results, ${ }^{3-7}$ data increasingly indicate that changes in mGluR3 are associated with schizophrenia and aging, ${ }^{8-22}$ encouraging this treatment strategy. Clinical trials were originally based on data from rodent models. ${ }^{23}$ However, the vast evolutionary expansion of the prefrontal association cortex ${ }^{24,25}$ suggests that understanding mGluR2/3 actions in primates may be key to translational success.

mGluR2/3 couple to Gi/Go and inhibit cAMP signaling. ${ }^{26}$ These receptors typically provide negative feedback on glutamate actions: presynaptic mGluR2/3 inhibit glutamate release, ${ }^{27}$ while in glia, they increase glutamate uptake from the synapse by increasing the expression of glial glutamate transporters. ${ }^{28}$ However, postsynaptic mGluR2/3 have also been observed, for example, mGluR3 in dendritic spines of hippocampal dentate granule cells, close to the glutamatergic synapses. ${ }^{29}$ Postsynaptic mGluR3 in CA3 pyramidal neurons have been reported to increase excitability by inhibiting $\mathrm{K}^{+}$conductance. ${ }^{30}$ The current data indicate that $\mathrm{mGluR2} / 3$ may also have a prominent, postsynaptic role in the newly evolved layer III circuits of the primate dorsolateral prefrontal cortex (dIPFC), which mediate working memory.

The dIPFC subserves our highest order cognitive abilities, generating the mental representations needed for working memory, abstract reasoning and executive functions. ${ }^{31}$ The cellular basis of working memory in primate dIPFC has been studied extensively using visuospatial working memory paradigms (Figure 1a), where the location of a cue must be remembered over a delay period of several seconds. Recordings from dIPFC uncovered 'Delay cells' that generate spatially tuned, persistent firing across the delay period when there is no sensory stimulation (Figure 1b). This firing arises from recurrent excitation within pyramidal cell microcircuits in deep layer III of primate dIPFC (Supplementary Figure 1), through $\mathrm{N}$-methyl-D-aspartate receptor (NMDAR) glutamatergic synapses on dendritic spines. ${ }^{32}$ The strength of these NMDAR connections is dynamically modulated by postsynaptic cAMPcalcium signaling, which opens potassium channels near the synapse, rapidly weakens connectivity, reduces Delay cell firing and impairs working memory (Figure 1c). ${ }^{33}$ Conversely, treatments that inhibit CAMP signaling in spines strengthen connectivity, enhance Delay cell firing and improve working memory. ${ }^{34,35}$ Thus, if $\mathrm{mGluR2} / 3$ are localized postsynaptically on spines in primate dIPFC, stimulation of mGluR2/3 may inhibit cAMP signaling and enhance Delay cell firing.

The integrity of dIPFC circuitry and the proper regulation of CAMP signaling are essential for healthy mental functioning, ${ }^{33}$ but they are altered in both age-related and psychiatric cognitive disorders. dIPFC function declines with age in both humans and monkeys, including age-related reductions in persistent neuronal firing because of disinhibited CAMP-potassium channel signaling and spine loss. ${ }^{36,37}$ Interestingly, mGluR2/3 expression decreases with advancing age in human dIPFC, $^{22}$ suggesting that reduced mGluR2/3 actions may contribute to disinhibited cAMP signaling and age-related cognitive decline. 
a

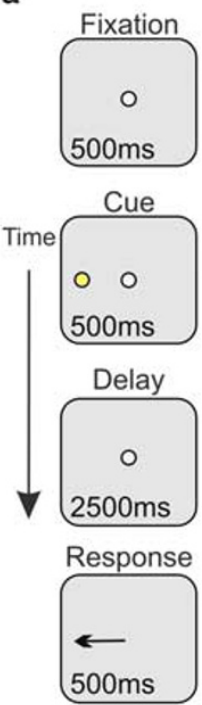

b

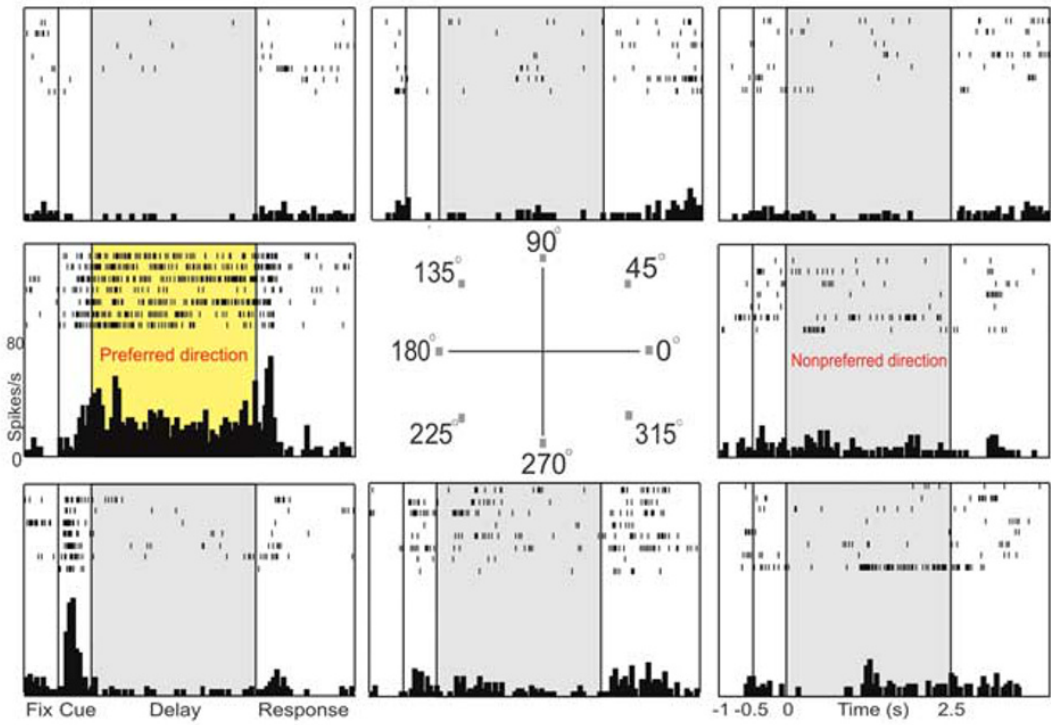

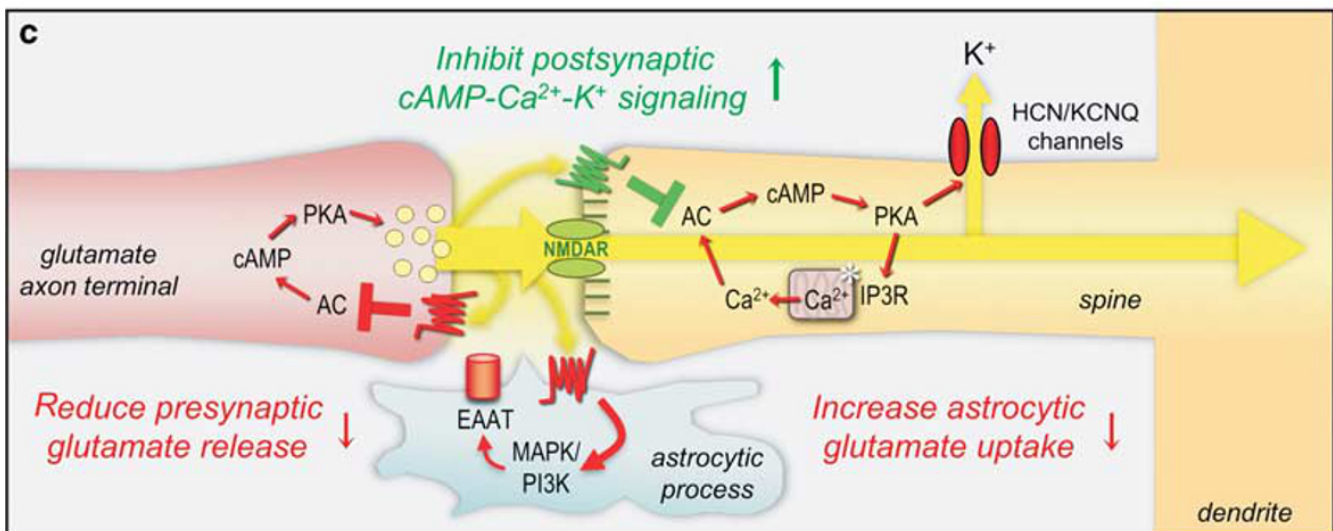

Figure 1. The experimental paradigm and working model. (a) The oculomotor delayed response task. The monkey fixates at a central point, and a visual cue appears at one of eight possible locations for $0.5 \mathrm{~s}$. The monkey must remember the location over a delay period ( $2.5 \mathrm{~s}$ ) and make a saccade to the correct location for juice reward. The cued location varies randomly from trial to trial. (b) A typical Delay cell, with spatially tuned persistent firing across the delay period in the neuron's preferred direction $\left(180^{\circ}\right)$ but not for other nonpreferred directions (e.g. $0^{\circ}$ ). (c) Working model of mGluR2/3 (metabotropic glutamate receptor) actions on a layer III dorsolateral prefrontal cortex (dIPFC) glutamatergic synapse. Postsynaptic mGluR2/3 (green) reside near the synapse and the calcium-storing spine apparatus (asterisk). They inhibit CAMP production, close hyperpolarization-activated cyclic nucleotide-gated (HCN) and Kv7 (KCNQ) channels, strengthen synaptic efficacy and enhance Delay cell firing. In contrast, mGluR2/3 receptors on axon terminals and astrocytes (red) reduce glutamate release and increases glutamate uptake, reducing Delay cell firing.

Schizophrenia is also associated with profound dIPFC dysfunction, including reduced blood oxygen level-dependent (BOLD) signals during working memory that correlate with thought disorder. ${ }^{38}$ Neuropathological studies have shown that deep layer III of dIPFC is especially afflicted in schizophrenia, with reduced neuropil, ${ }^{39,40}$ marked spine loss ${ }^{41}$ and compensatory weakening of GABAergic lateral inhibition. ${ }^{42}$ Schizophrenia is associated with insults to glutamate NMDAR actions ${ }^{43,44}$ and with disinhibited CAMP signaling, for example, disrupted in schizophrenia 1 would anchor phosphodiesterase 4A in dIPFC spines, positioned to regulate the positive feedback cycle of CAMP-PKAcalcium signaling. ${ }^{45,46}$ Insults to disrupted in schizophrenia 1 and phosphodiesterase $4 \mathrm{~A}$ are linked to increased risk of illness. ${ }^{47,48}$ Importantly, genetic alterations in mGluR3 are increasingly linked to schizophrenia, ${ }^{8-21}$ including altered dIPFC activation and poorer cognitive performance. ${ }^{9,11}$ In particular, there is reduced mGluR3 protein in schizophrenia dIPFC, and an increase in GCPII, the enzyme that catabolizes the endogenous mGluR3 ligand, NAAG. ${ }^{20}$
mGluR2/3 agonists have been a focus of drug development for schizophrenia, based on findings that NMDAR antagonists increase, whereas $\mathrm{mGluR2} / 3$ agonists decrease, glutamate release in rodent medial PFC. ${ }^{23,27,49}$ However, the results of clinical trials have been mixed, ${ }^{3-7}$ emphasizing the need for understanding mGluR2/3 actions in primate dIPFC. Here we examined mGluR2/3 mechanisms in the dIPFC of rhesus macaque monkeys. Immunoelectron microscopy revealed their subcellular localization in layer III circuits. The effects of mGluR2/3 stimulation on neural firing patterns were examined using iontophoretic application of drugs directly onto dIPFC Delay cells, while monkeys performed a spatial working memory task. Parallel behavioral studies examined the effects of systemic administration of mGluR2/3 agents on cognitive performance in young adult and aged monkeys, and intra-PFC administration in rats. We report that besides their proverbial presynaptic and glial localization, postsynaptic mGluR2/3 are overtly expressed on dendritic spine synapses in layer III dIPFC. Consistent with this pattern of localization, mGluR2/3 agonists produced an inverted- $U$ effect on both the neuronal 
representation and the behavioral performance of working memory, where low doses enhanced neuronal firing and cognitive performance. These results suggest that low doses of mGluR2/3 agonists have therapeutic potential for cognitive disorders, and that they may act by strengthening postsynaptic connections in dIPFC.

\section{MATERIALS AND METHODS}

All research was conducted under the guidelines of the $\mathrm{NIH}$ and Yale IACUC.

\section{Immunoelectron microscopy}

Four adult female rhesus macaques (9-11 years) were perfused transcardially with artificial cerebrospinal fluid, followed by $4 \%$ paraformaldehyde, $0.05 \%$ glutaraldehyde and $0.18 \%$ picric acid in $0.1 \mathrm{~m}$ phosphate buffer. The brains were vibrosliced coronally at $70 \mu \mathrm{m}$, and sections of dIPFC were processed for peroxidase or gold immunocytochemistry. mGluR2/3 were labeled with rabbit antibodies against a 13-amino-acid sequence of the shared $C$ terminus of mGluR2 and mGluR3 $\left(0.8 \mu \mathrm{g} \mathrm{ml}^{-1}\right.$; ab6438; Abcam, Cambridge, MA, USA), thus marking the cytoplasmic aspect of the plasma membrane (Figure 2). Quantitative assessments were performed on peroxidase-labeled material using random, $21.6 \mu \mathrm{m}^{2}$ fields of the dIPFC neuropil (original magnification $\times 30000$ ), captured from the 4th surface-most ultrathin section of each plastic block: 5 fields per block and 5 blocks per brain. Detailed procedures have been described in Paspalas et al. $^{50}$

\section{Electrophysiology and iontophoresis}

Two adult male rhesus macaques (14 and 16 years) were trained to perform an oculomotor delayed response task, a test of visuospatial working memory. In this task, the monkey remembers the location of a briefly presented cue over a delay period, and makes an eye movement to the correct location to receive liquid reward (Figure 1a). The cued location varies from trial to trial, requiring constant updating of the spatial information held in working memory. Single-unit recordings of Delay cells (Figure 1b) were conducted in dIPFC, at the caudal principal sulcus, essential for oculomotor delayed response performance. Following stable recording under control conditions, mGluR2/3 agents were applied via iontophoresis; small electrical currents (5-100nA) delivered minute amounts of drug to the recording site insufficient to alter behavior. The following drugs were used: the mGluR2/3 agonists, (2R, 4R)-APDC or LY379268, the mGluR2/3 antagonist, LY341495 disodium salt, and the CAMP analog, 8-Br-CAMP sodium salt. All agents were from Tocris Bioscience (Minneapolis, MN, USA), and were dissolved in distilled water (pH adjusted to 7.5-8.5 for APDC and LY379268). $d^{\prime}$ was calculated as a

Figure 2. Subcellular localization of mGluR2/3 (metabotropic glutamate receptor) in primate dorsolateral prefrontal cortex (dIPFC). Color-coded arrowheads point to immunogold labeling in axons (red), spines (yellow) and astrocytes (blue). (a and b) Presynaptic mGluR2/3 are present on extrasynaptic and perisynaptic membranes (a) and within the synapse per se (b) in glutamatergic-like axospinous synapses. (c and d) Postsynaptic mGluR2/3 on spine membranes appear perisynaptically (c) and in association with the spine apparatus (asterisk; c and d). Intervaricose axons in (c) are also labeled. (e) Both pre- and postsynaptic mGluR2/3 in a single axospinous synapse. Here the receptors are on the perisynaptic membranes flanking the glutamatergic-like asymmetric synapse. (f) $\mathrm{mGluR2} / 3$ are commonly expressed in astrocytic processes ensheathing glutamatergic-like synapses. (g) Quantitative assessment of the prevalence of mGluR2/3 in various cellular profiles in layer III of the dIPFC neuropil; expressed as mGluR2/3 profile (e.g. axon) per total mGluR2/3 profiles. Besides the proverbial axonal and glial mGluR2/3, the data establish mGluR2/3 postsynaptic expression in spines, and occasionally the shafts of dendrites. Non-determined (ND) are profiles that could not be unequivocally identified. as, astrocyte; ax; axon; den, dendrite; sp, spine; synapses are between black arrows. Scale bars: $200 \mathrm{~nm}$. measure of the strength of spatial tuning using the formula: $d^{\prime}=\left(\right.$ mean $_{\text {pref }}-$ mean $\left._{\text {nonpref }}\right) / \sqrt{\left(s d_{\text {pref }}^{2}+s d_{\text {nonpref }}^{2}\right) / 2}$ Detailed methods for electrophysiology and iontophoresis have been described in Wang et $a .^{32}$ and Yang et al. ${ }^{51}$

\section{Behavioral assessments}

Monkey systemic administration. The effects of systemically administered mGluR2/3 agents were examined in younger (7-17 years) and aged

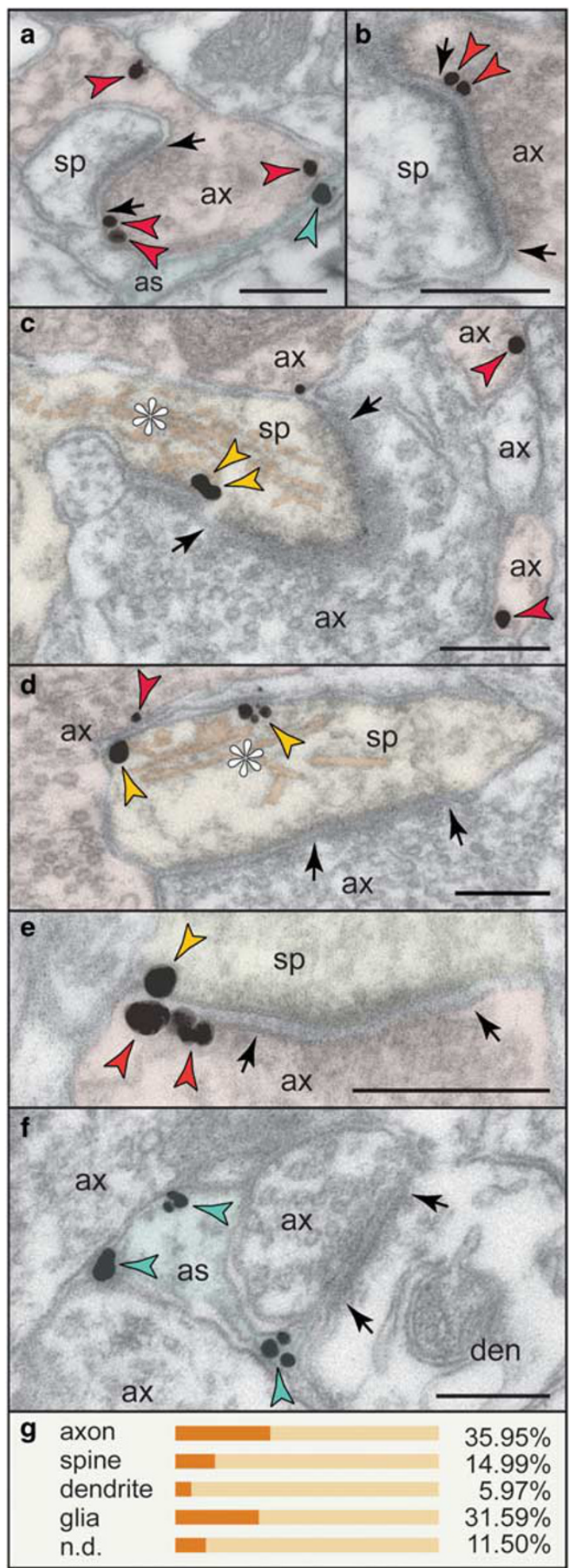


(18-30 years) adult female and male rhesus macaques. Monkeys were trained on a manual spatial working memory task in a Wisconsin General Testing Apparatus. ${ }^{52}$ The delay lengths were adjusted for each animal so that they had a stable baseline performance of $60-80 \%$ correct. Drugs were delivered primarily by intramuscular injection, except for two monkeys who were able to receive oral administration because of reliable ingestion of the compound. A wide range of doses of the mGluR2/3 agonists APDC (0.0001-1.0 $\left.\mathrm{mg} \mathrm{kg}^{-1}\right)$ or LY379268 (0.0001-0.05 $\mathrm{mg} \mathrm{kg}^{-1}$ ) was administered $60 \mathrm{~min}$ before testing and compared with vehicle control. To test for actions at mGluR2/3, the antagonist LY341495 (0.01$0.1 \mathrm{mg} \mathrm{kg}^{-1}$ ) or vehicle was administered $120 \mathrm{~min}$ before testing. Drugs were dissolved and diluted in saline for intramuscular injection or in water for oral administration, except for LY341495, which was dissolved in dimethyl sulfoxide and then diluted with saline/water.

Rat intra-PFC infusion. The effects of $\mathrm{mGluR2} / 3$ agents in rats were tested through direct drug infusions into the medial PFC. Young male SpragueDawley rats (5-14 months) were implanted with chronic infusion cannulae directed above the prelimbic PFC (anterior-posterior $+3.2 \mathrm{~mm}$; mediallateral $\pm .75 \mathrm{~mm}$; dorsal-ventral $-4.2 \mathrm{~mm}$ ). Rats were trained in a delayed alternation task in a T-maze. The animals started at the bottom of the ' $\mathrm{T}$ ' and were rewarded for entering either arm for the first trial. In each subsequent trial, they were rewarded only for choosing the arm that they had not visited in the previous trial. Between trials, they were picked up and returned to the start box and waited over a delay period. Thus, they had to update and maintain spatial information over the delay period for each trial. The delay lengths were adjusted for each rat to maintain a stable baseline of $60-80 \%$ before treatment. A range of doses of APDC (0.0001$0.01 \mu \mathrm{g} / 0.5 \mu \mathrm{l}$, which is $1.15-115 \mu \mathrm{m})$ was infused bilaterally into PFC $(0.5 \mu \mathrm{l}$ per side) $15 \mathrm{~min}$ before testing and compared with saline vehicle.

All agents were purchased from Tocris Bioscience. After an initial assessment that higher doses of drug were safe, dose administration was randomized. The experimenters testing the animals on cognitive tasks were blind to drug treatment condition. Detailed behavioral and pharmacological methods have been described in Gamo et al. ${ }^{53,54}$

\section{Statistical analysis}

Data were analyzed using the IBM SPSS Statistics version 23 (IBM, Armonk, NY, USA) and MATLAB (The MathWorks, Natick, MA, USA). Statistical analysis of drug effects in the electrophysiological and behavioral experiments all used within subjects comparisons, with repeated one- or two-way analysis of variance (ANOVA) or two-tailed, paired-samples $t$-tests. The number of animals used was informed by previous studies, and assumptions for specific statistical tests were met. $P<0.05$ was predetermined as the threshold for statistical significance.

\section{RESULTS}

Subcellular localization of mGluR2/3 in primate dIPFC

Immunoelectron microscopy of mGluR2/3 revealed a complex expression pattern with pre- and postsynaptic as well as glial localization in layer III of the primate dIPFC; quantitatively summarized in Figure 2g.

Presynaptic mGluR2/3 were most commonly observed. Glutamatergic-like axons expressed mGluR2/3 autoreceptors extrasynaptically and perisynaptically at membranes flanking asymmetric synapses (Figure 2a) as well as within the synapse (Figure 2b), the former allowing the detection of glutamate spillover beyond the active zone. Bundled intervaricose segments (i.e. preterminal axons) were also labeled for mGluR2/3 (Figure 2c).

Postsynaptic expression of mGluR2/3 was predominantly in the spines and seldom the shafts of dendrites. In spines, receptors were visualized within the active zone of the synapse or more commonly perisynaptically (Figure 2c). mGluR2/3 were also observed at extrasynaptic sites in spines, where they selectively marked the plasma membrane facing the spine apparatus (i.e. the calcium-storing extension of smooth endoplasmic reticulum into the spine) (Figures $2 \mathrm{c}$ and d). Hence, postsynaptic mGluR2/3 are well positioned to inhibit the calcium-cAMP signaling in dIPFC layer III spines and strengthen network firing. As shown in Figure 2e, an individual glutamatergic-like axospinous synapse could be expressing both pre- and postsynaptic mGluR2/3, a possible substrate for inverted-U influences on neuronal firing (see below).

Astrocytic processes were distinctly labeled, accounting for the second most prevalent mGluR2/3-expressing cellular profile. Particularly, mGluR2/3 were found at the perisynaptic astrocytic processes ensheathing glutamatergic-like axospinous and rarely axodendritic synapses, where they are positioned to regulate glial uptake of glutamate from the synaptic cleft (Figures $2 a$ and f).

mGluR2/3 actions on working memory-related activity in primate dIPFC

mGluR2/3 stimulation has an inverted-U effect on Delay cell firing. We first examined the effect of the mGluR2/3 agonist APDC on Delay cell firing. As illustrated in Figure 3a, iontophoresis of a low dose of APDC ( $15 \mathrm{nA}$ ) increased Delay firing preferentially for the neuron's preferred direction, leading to stronger neuronal representations of visuospace, whereas a higher dose $(60 n A)$ lowered the firing rate.

At the population level $(n=43)$, low doses $(5-15 n A)$ of APDC significantly enhanced Delay cell firing during the delay period for the neurons' preferred directions (Figures $3 \mathrm{~b}$ and $\mathrm{c}$; $\left.t_{\text {dep }}(42)=-5.132, P<0.001\right)$. The increased firing was greater for the neurons' preferred direction than for nonpreferred directions, leading to enhanced spatial tuning (Supplementary Figure 2; repeated two-way ANOVA, $\left.F_{\text {direction } \times \text { drug }}(1,42)=16.479, P<0.001\right)$. Tuning was also improved as quantified by $d^{\prime}$ (Figure $3 \mathrm{~d}$; $\left.t_{\text {dep }}(42)=-4.548, P<0.001\right)$. Thus, low doses of APDC enhanced the neural representation of visuospace.

In a subset of Delay cells $(n=16)$, we additionally tested higher APDC doses (20-100 nA). There was a significant reduction of Delay firing compared with low doses (Figure $3 c$; $t_{\text {dep }}(15)=2.996$, $P=0.009)$, which was also reflected in decreased spatial tuning quantified by $d^{\prime}$ (Figure $3 \mathrm{~d} ; t_{\mathrm{dep}}(15)=5.007, P<0.001$ ).

Overall, APDC produced an inverted-U dose-response on Delay firing (Figure 3c; Huynh-Feldt-corrected repeated one-way ANOVA, $F(1.532,22.977)=4.321, \quad P=0.034)$; quadratic trend, $F(1,15)=19.344, P=0.001)$. An inverted-U effect was also observed for spatial tuning quantified by $d^{\prime}$ (Figure $3 \mathrm{~d}$; repeated one-way ANOVA, $\mathrm{F}(2,30)=6.906, P=0.003$; quadratic trend, $\mathrm{F}(1,15)=13.038$,

Figure 3. mGluR2/3 (metabotropic glutamate receptor) stimulation had an inverted-U effect on Delay cell firing. (a) Example of a Delay cell where APDC had an inverted-U effect on neuronal firing. APDC at $15 \mathrm{nA}$ increased Delay cell firing and spatial tuning ( $\left.d^{\prime}\right)$, leading to enhanced neuronal representation of visuospace. APDC at $60 \mathrm{nA}$ eroded the enhancing effects of low dose. For each condition, left panel is the neuron's preferred direction; right panel is the nonpreferred direction; upper panel is rastergram, with each row as a single trial and each short line as a spike; lower panel is histogram with timebins of 50ms. (b) Population histogram of 43 Delay cells in Control and APDC low-dose condition; mean \pm s.e.m. APDC at a low-dose range (5-15 nA) preferentially enhanced Delay firing for the neurons' preferred directions. (c and d) Population Delay firing (c) and $d^{\prime}$ (d) in Control, APDC low-dose and APDC high-dose condition; mean \pm s.e.m. Low dose of APDC (5-15 nA) significantly enhanced Delay firing and spatial tuning $(n=43)$; high dose $(20-100 \mathrm{nA})$ eroded the enhancing effect of low dose $(n=16)$, and thus is not different from Control condition. (e) Population histogram of 19 Delay cells in Control and LY379268 low-dose condition; mean \pm s.e.m. LY379268 at a low-dose range (5-15 nA) specifically enhanced Delay firing for the neurons' preferred but not nonpreferred directions. 
$P=0.003)$. We also calculated a normalized dose-response curve with all the neurons and all the doses tested, which demonstrated enhancing effects on Delay firing and $d^{\prime}$ with 5-15 nA of APDC, but not with higher doses (Supplementary Figure 3). Thus, low doses of APDC increased firing and enhanced spatial tuning, whereas these effects eroded at higher doses.
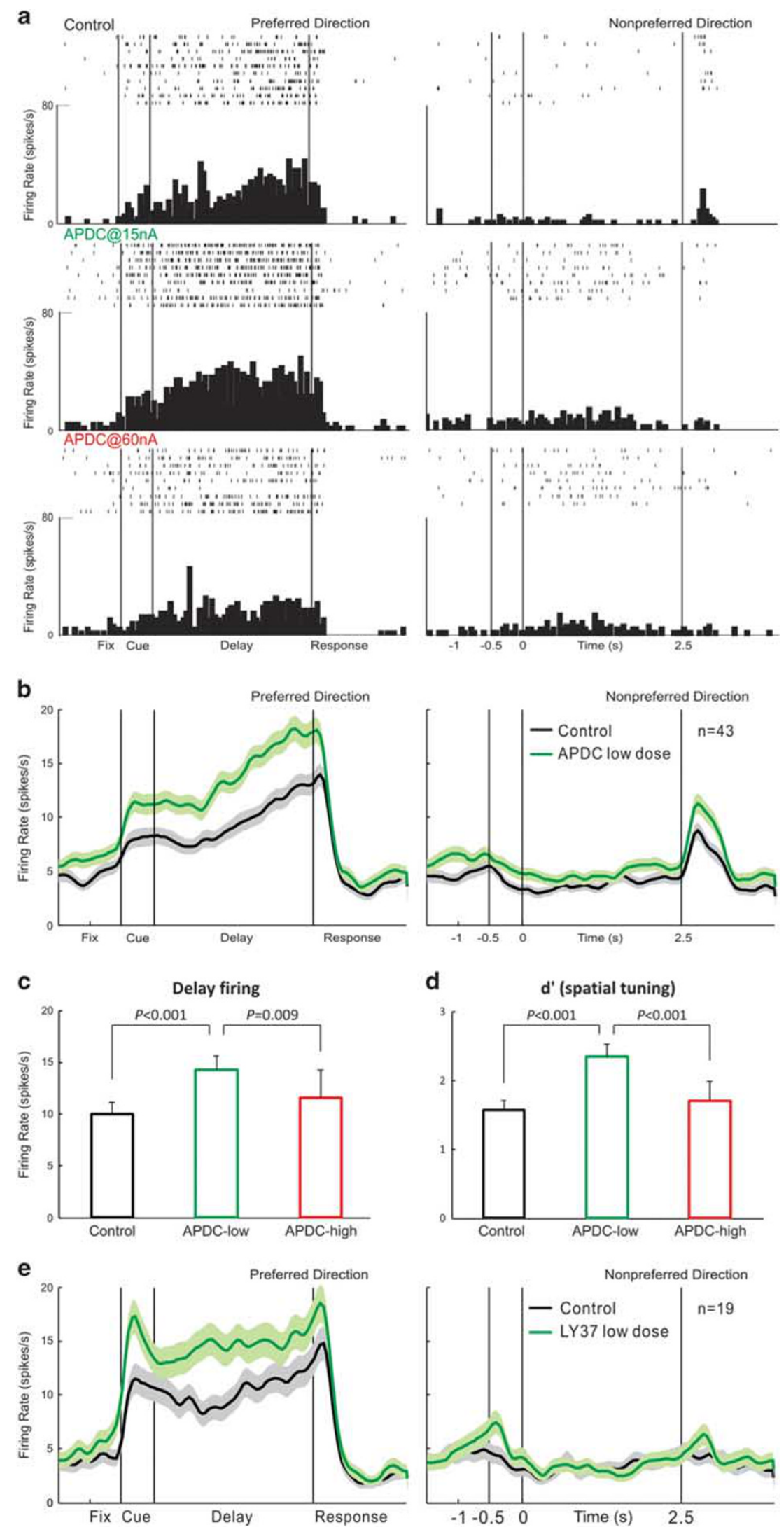
Replication of low-dose enhancing effects with an additional mGluR2/3 agonist. The effects of APDC were compared with another mGluR2/3 agonist, LY379268 $(n=19)$. Similar to APDC, low doses of LY379268 (5-15 nA) enhanced Delay cell firing for the neurons' preferred direction (Figure $3 e ; t_{\text {dep }}(18)=-4.612, P<0.001$ ). The increased firing was very specific for the preferred direction (Figure $3 e$ and Supplementary Figure 4a; repeated two-way ANOVA, $\left.\mathrm{F}_{\text {direction } \times \text { drug }}(1,18)=29.107, P<0.001\right)$, leading to enhanced spatial tuning and $d^{\prime}$ (Supplementary Figure $4 \mathrm{~b} ; t_{\text {dep }}(18)=-3.644, P=0.002$ ).

Higher doses of LY379268 (30-60nA) had a mixed effect on neuronal firing $(n=13)$, causing reductions in a subset of cells but nonspecific increases in others, and thus at the population level maintained the enhancing effect on Delay cell firing compared with Control condition (Supplementary Figure 4a; $t_{\text {dep }}(12)=-$ 2.355, $P=0.036)$. However, higher doses of LY379268 eroded the improving effect of low dose on spatial tuning, causing the $d^{\prime}$ to fall to the level that was not significantly different from the Control condition (Supplementary Figure $4 \mathrm{~b} ; P>0.9$ ), thus compromising the specificity of working memory representations. The nonspecific actions of LY379268 at high doses may arise from its off-target interactions with the dopamine system, ${ }^{55}$ but this issue remains controversial ${ }^{56,57}$ and there may be other possibilities underlying the mixed effect at high doses.

mGluR2/3 antagonist reverses APDC beneficial actions. To test for actions at mGluR2/3, we challenged low doses of APDC with the mGluR2/3 antagonist, LY341495. Co-iontophoresis of LY341495 reversed the enhancing effects of APDC on Delay cell firing (Figures $4 a$ and $b ; n=13)$. Low doses of APDC (5-15 nA) significantly enhanced Delay firing for the neurons' preferred directions $\left(t_{\text {dep }}(12)=-4.258, P=0.001\right)$, and this increase was reversed by coapplication of LY341495 $(10-15 n A)\left(t_{\text {dep }}(12)=3.998, P=0.002\right)$. These results are consistent with drug actions at mGluR2/3.

CAMP analog reverses the enhancing effects of mGluR2/3 stimulation. mGluR2/3 typically act via Gi/Go to inhibit cAMPPKA signaling. Previous findings have shown that inhibiting CAMP signaling closes CAMP/PKA-regulated potassium channels and enhances Delay cell firing. ${ }^{35}$ Thus, we examined whether the enhancing effects of APDC could be reversed by increasing
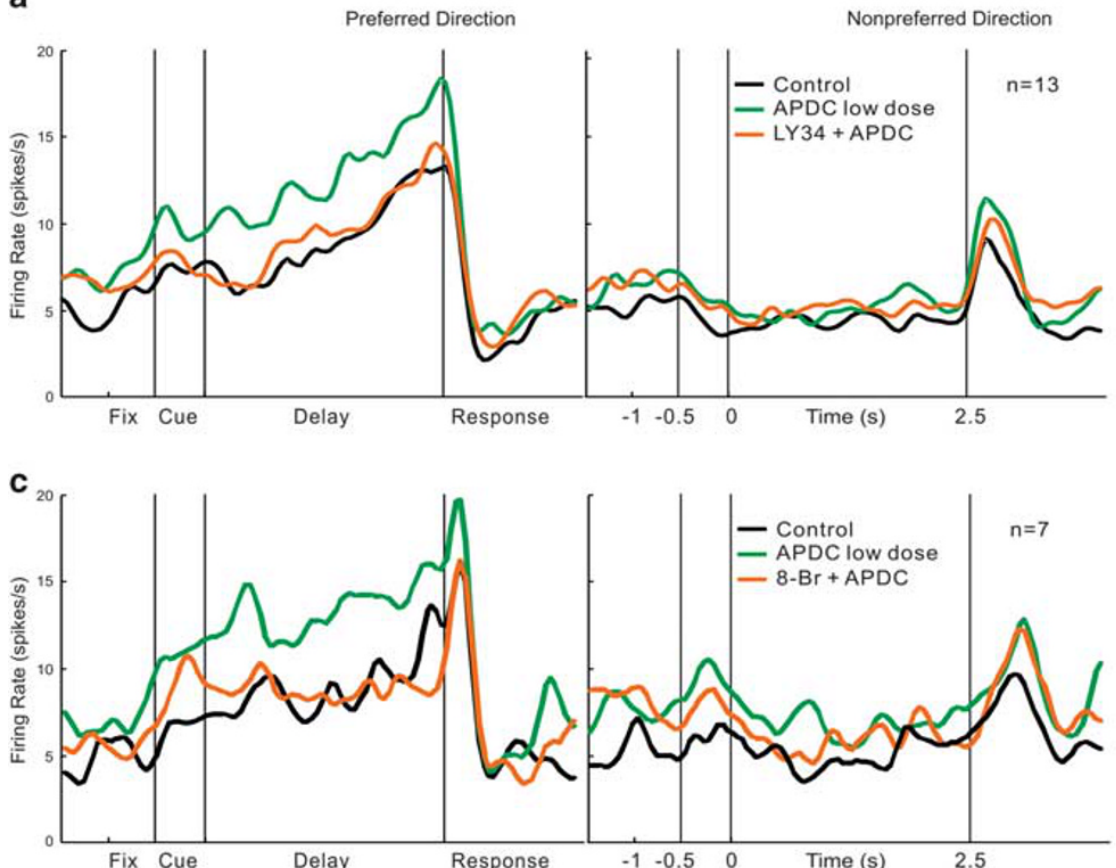

b
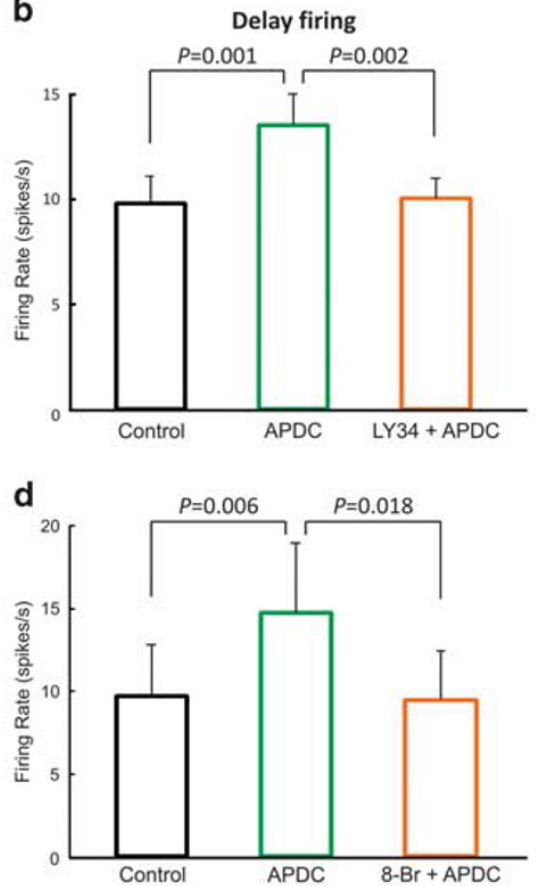

Figure 4. mGluR2/3 (metabotropic glutamate receptor) antagonist or CAMP analog reversed the enhancing effects of mGluR2/3 stimulation. (a and b) Population histogram (a) and Delay firing (b) of 13 Delay cells in Control, APDC low-dose and LY341495+APDC low-dose condition; mean+s.e.m. Low doses of APDC (5-15 nA) significantly enhanced Delay firing, and the increase was reversed by coapplication of the mGluR2/3 antagonist, LY341495 (10-15 nA), consistent with APDC actions on mGluR2/3. (c and d) Population histogram (c) and Delay firing (d) of 7 Delay cells in Control, APDC low-dose and 8-Br-cAMP+APDC low-dose condition; mean+s.e.m. Low doses of APDC (5-15 nA) significantly enhanced Delay firing, and the increase was reversed by coapplication of 8-Br-cAMP (10 nA), indicating that mGluR2/3 act by inhibiting CAMP signaling.

Figure 5. mGluR2/3 (metabotropic glutamate receptor) agonists enhanced working memory performance in primates and in rodents. mGluR2/3 agonists have inverted-U effects on working memory performance. (a) Dose-response curves of a young adult and an aged monkey to APDC. (b) Average response of 17 monkeys to APDC; mean \pm s.e.m. ${ }^{*} P<0.05 ;{ }^{* *} P<0.01$ compared with vehicle. (c) The replicable, enhancing effects of APDC were reversed by pre-treatment with LY341495 $(n=10)$. LY341495 alone did not change performance compared with vehicle $(P>0.5)$. (d) Dose-response curves of a young adult and an aged monkey to LY379268. \#= doses causing nausea/vomiting. (e) Average response of 15 monkeys to LY379268; mean \pm s.e.m. $* * P<0.01$ compared with vehicle. (f) The replicable, enhancing effects of LY379268 were reversed by pre-treatment with LY341495 $(n=5)$. LY341495 alone did not change performance compared with vehicle $(P>0.1)$. (g) Average response of 10 rats to intra-PFC infusion of APDC; mean \pm s.e.m. Low $(0.0001 \mu \mathrm{g} / 0.5 \mu \mathrm{l})$ but not high $(0.001-0.01 \mu \mathrm{g} / 0.5 \mu \mathrm{l})$ doses of APDC significantly enhanced working memory performance. 
CAMP-PKA signaling with 8-Br-CAMP, a cell-permeable CAMP analog and an activator of PKA (Figures $4 c$ and $d ; n=7$ ). As predicted, low doses of APDC (5-15 nA) significantly enhanced Delay firing for the preferred directions $\left(t_{\mathrm{dep}}(6)=-4.107, P=0.006\right)$, and subsequent co-iontophoresis of 8 -Br-cAMP $(10 \mathrm{nA})$ significantly reversed the enhancing effects of APDC $\left(t_{\text {dep }}(6)=3.223\right.$, $P=0.018)$. When tested separately, 8-Br-cAMP (10 nA) on its own had no significant effect on neuronal firing (Supplementary

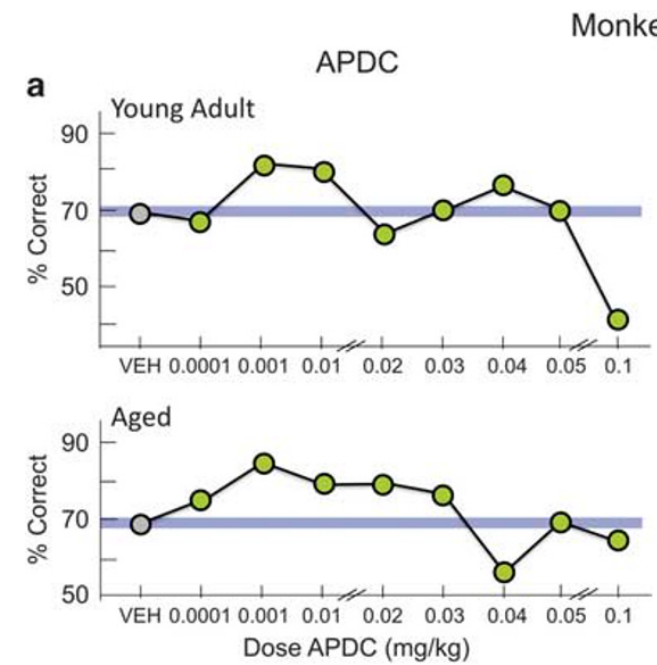

Systemic
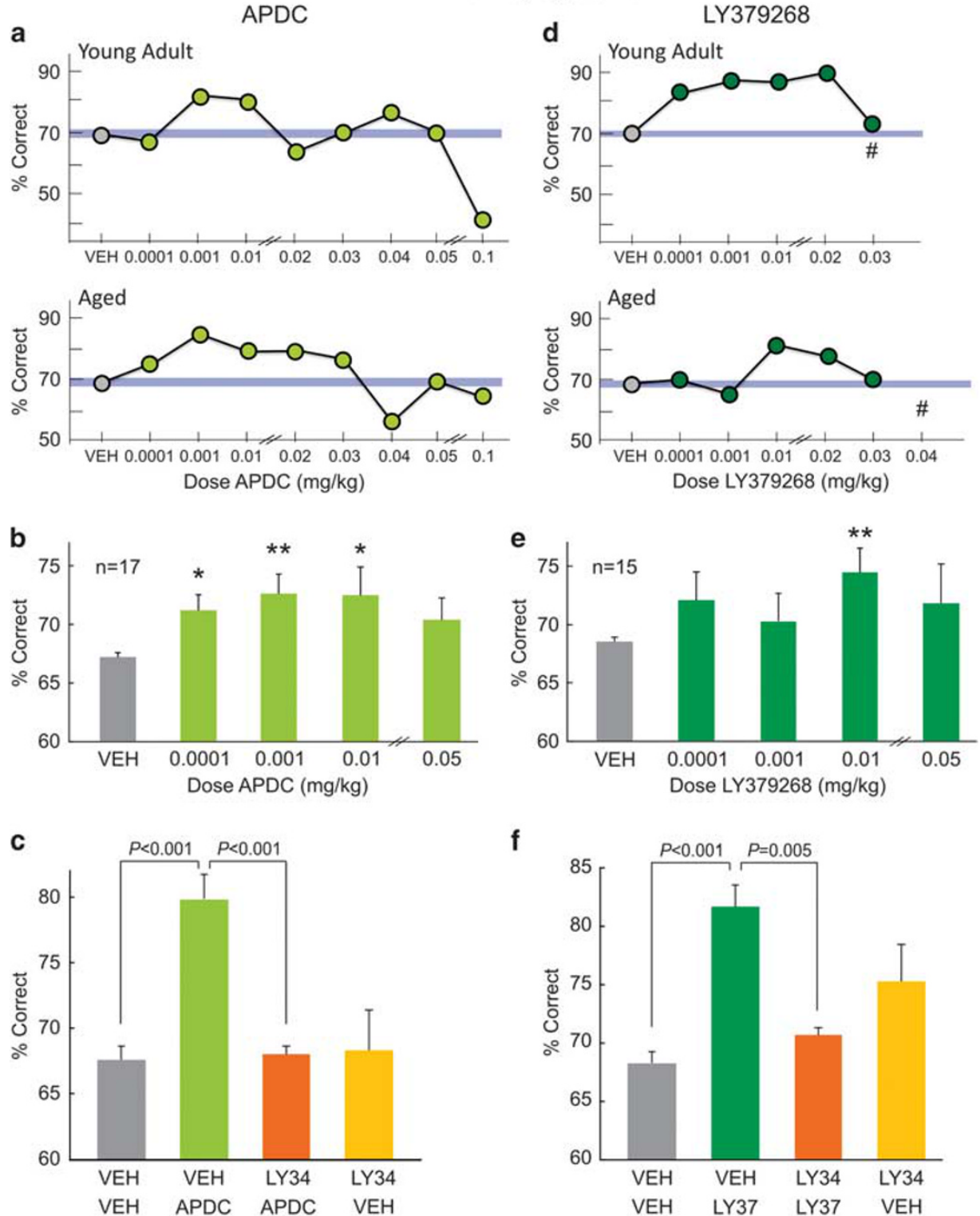

$\mathbf{f}$

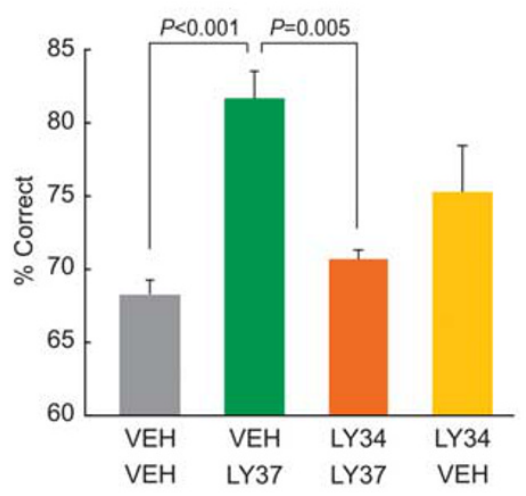

g

Rat IntraPFC

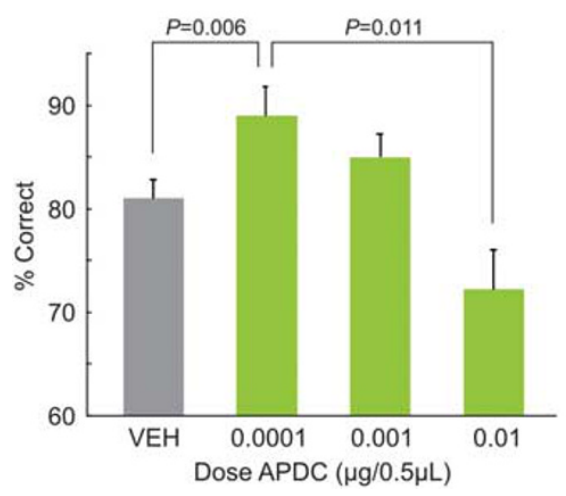


Figure 5). Thus, the reversal of APDC's enhancing effect with 8-BrCAMP at $10 \mathrm{nA}$ was not simply an additive effect of combined drug actions. These data support a physiological interaction between mGluR2/3 and CAMP signaling. The results indicate that the enhancing effects of $m G l u R 2 / 3$ stimulation are likely due to inhibition of CAMP-PKA signaling.

Summary of physiological findings. In summary, mGluR2/3 stimulation produced an inverted-U dose-response on neuronal firing, where low doses of agonists enhanced, and high doses eroded, neural representations of visual spatial working memory. The increased Delay cell firing following mGluR2/3 stimulation involved inhibition of CAMP-PKA signaling, consistent with strengthened dIPFC network connections.

mGluR2/3 agonists enhance working memory performance in both primates and rodents

The electrophysiological data suggest that low doses of mGluR2/3 agonist should improve working memory performance. This hypothesis was tested with systemic administration of drugs in monkeys, and intra-PFC infusions in rats.

Systemic administration of mGluR2/3 agents in monkeys. The effects of APDC on spatial working memory performance were examined in young adult and aged monkeys $(n=17)$. Similar to its effects on dIPFC Delay cells, APDC produced an inverted-U doseresponse on behavioral performance (Figure 5a shows the doseresponse curves of two individual monkeys). The inverted-U drug effect was also observed at the population level (Figure 5b). Lower doses of APDC $\left(0.0001-0.01 \mathrm{mg} \mathrm{kg}^{-1}\right)$ significantly improved accuracy (Huynh-Feldt-corrected repeated one-way ANOVA, F(2.018, $32.293)=3.38, P=0.046$ ), with all doses improving working memory performance (vehicle vs APDC $0.0001 \mathrm{mg} \mathrm{kg}^{-1}: t_{\text {dep }}(16)=-2.75$, $P=0.014$; vehicle vs APDC $0.001 \mathrm{mg} \mathrm{kg}^{-1}: t_{\text {dep }}(16)=-3.643$, $P=0.002$; vehicle vs APDC $0.01 \mathrm{mg} \mathrm{kg}^{-1}: t_{\mathrm{dep}}(16)=-2.349, P=0.032$ ).

At higher doses $\left(0.02-0.1 \mathrm{mg} \mathrm{kg}^{-1}\right)$, the effects of APDC were mixed, with some monkeys being improved, and others impaired or unchanged, leading to a nonsignificant result (Huynh-Feldtcorrected repeated one-way ANOVA, $F(3.569,57.097)=0.903$, $P=0.459)$. A subset of monkeys were given higher doses of APDC (0.5-1.0 $\left.\mathrm{mg} \mathrm{kg}^{-1}\right)$; these doses also had mixed effects on working memory performance $(P>0.1)$. There was no evidence of agerelated differences in drug potency or efficacy $(P>0.1)$, and no side effects were observed even after high doses of APDC. Improvement was found with either oral or intramuscular routes of administration.

The beneficial effects of low doses of APDC were challenged with the mGluR2/3 antagonist, LY341495, to test for drug actions at mGluR2/3 $(n=10)$. A dose of APDC that produced replicable improvement in working memory performance was identified for each monkey, and this dose was then challenged with LY341495. Pre-treatment with LY341495 blocked the enhancing effects of APDC, consistent with drug actions at mGluR2/3 (Figure $5 \mathrm{c}$; repeated two-way ANOVA, $\left.\mathrm{F}_{\mathrm{APDC} \times \mathrm{LY} 34}(1,9)=20.017, P=0.002\right)$.

The behavioral effects of APDC were compared with the mGluR2/3 agonist LY379268 $(n=15)$. LY379268 also produced an inverted-U dose-response on working memory performance (Figures $5 \mathrm{~d}$ and e). Lower doses $\left(0.0001-0.01 \mathrm{mg} \mathrm{kg}^{-1}\right.$ ) significantly improved accuracy (repeated one-way ANOVA, $F(3,42)=$ $2.972, P=0.042)$, with significant improvements at $0.01 \mathrm{mg} \mathrm{kg}^{-1}$ $\left(t_{\text {dep }}(14)=-3.079, P=0.008\right)$. Higher doses of LY379268 (0.02-0.05 $\mathrm{mg} \mathrm{kg}^{-1}$ ) had mixed, nonsignificant effects on performance (repeated one-way ANOVA, $F(4,56)=1.914, P=0.121$ ). As with APDC, there was no difference in drug potency between young vs aged monkeys $(P>0.1)$. However, in contrast to APDC, high doses of LY379268 often produced nausea/vomiting (Figure $5 \mathrm{~d}$, marked with \#), which may be related to the drug acting as a dopamine
D2 receptor agonist at high doses. ${ }^{55}$ These side effects were not observed following the low, enhancing doses, but precluded drug testing of doses $>0.05 \mathrm{mg} \mathrm{kg}^{-1}$. As with APDC, the beneficial effects of low doses of LY379268 were replicated, and were blocked by pre-treatment with the mGluR2/3 antagonist, LY341495 (Figure 5f; repeated two-way ANOVA, $F_{\text {LY37 } \times \text { LY34 }}(1,4)=24.575$, $P=0.008)$.

Intra-PFC infusion of $m G / u R 2 / 3$ agonist in rats. Last, we examined the effects of intra-PFC infusions of mGluR2/3 agonist in rats performing a T-maze spatial working memory task $(n=10)$. Local infusion of APDC into prelimbic PFC produced an inverted-U dose-response on working memory performance (Figure $5 \mathrm{~g}$; repeated one-way ANOVA, $F(3,21)=7.685, P=0.001$; quadratic trend, $F(1,7)=13.324, P=0.008)$. A very low dose of APDC $(0.0001 \mu \mathrm{g} / 0.5 \mu \mathrm{l}$, which is $1.15 \mu \mathrm{m})$ significantly enhanced working memory performance $\left(t_{\text {dep }}(9)=-3.539, P=0.006\right)$, but this beneficial effect was eroded at a higher dose $(0.01 \mu \mathrm{g} / 0.5 \mu \mathrm{l}$, which is $\left.115 \mu \mathrm{m} ; t_{\mathrm{dep}}(8)=3.278, P=0.011\right)$.

Summary of behavioral findings. In summary, administration of mGluR2/3 agonists produces an inverted- $U$ dose-response at the behavioral level as well, with low doses enhancing working memory performance in both rodents and primates.

\section{DISCUSSION}

\section{Summary}

Here we report a novel mGluR2/3 mechanism in the primate dIPFC circuits directly relevant to higher cognitive function. Previous research has focused on presynaptic and glial localization/actions of $\mathrm{mGluR2} / 3$, which reduce glutamate levels in the synapse, and reduce neuronal firing. Our data reveal that, in layer III of primate dIPFC, mGluR2/3 are also expressed postsynaptically in the axospinous synapse. Pharmacological stimulation of $m G l u R 2 / 3$ in primate dIPFC also had an unexpected excitatory effect. It caused an inverted-U dose-response on Delay cell firing, where low doses of mGluR2/3 agonists increased firing and enhanced the persistent representations of visuospace, whereas higher doses had no effect or eroded representations. These physiological findings were echoed in the behavioral data, where systemic administration of mGluR2/3 agonists similarly produced an inverted-U shaped dose-response. Low doses of mGluR2/3 agonists significantly improved performance in working memory task, whereas higher doses had inconsistent effects on behavior. As clinical trials of mGluR2/3 agonists in patients with schizophrenia have used higher doses with mixed effects, these data in monkeys suggest that dose range may be a key factor for a more precise targeting of drug actions within the circuitry and thus for developing mGluR2/3 agonists as cognitive enhancers.

mGluR2/3 and the glutamate hypothesis of schizophrenia

Systemic administration of NMDAR antagonists has become a widespread animal model of schizophrenia, as these agents can mimic many symptoms of the illness. ${ }^{58}$ Historically, studies of rodent PFC have shown disinhibited neuronal firing and increased glutamate release following systemic blockade with NMDAR antagonists. ${ }^{23}$ These rodent studies generally sampled from layer $\mathrm{V}$ neurons, which are the most prevalent in rodent PFC (see below). mGluR2/3 agonists were conceptually designed to attenuate these high levels of glutamate efflux and to protect against overexcitability. However, recent evidence suggests that layer III dIPFC pyramidal cells are not metabolically overactive, but rather are underactive in schizophrenia, ${ }^{59}$ consistent with loss of spines and reduction in recurrent excitatory firing in these critical layer III microcircuits. ${ }^{38,41}$ Similarly, Delay neurons in monkey dIPFC show reduced firing, not increased firing, following NMDAR 
blockade (local or systemic). ${ }^{32}$ Thus, efforts to reduce glutamate release in these circuits would likely worsen rather than ameliorate cognitive deficits. The current study indicates that mGluR2/3 stimulation may still benefit these circuits, but by increasing firing and enhancing neural representations, presumably through postsynaptic drug actions.

Postsynaptic mGluR2/3 may contribute to the enhancing effects on Delay cell firing

Our electron microscopic data demonstrate the postsynaptic localization of mGluR2/3 in spines of layer III pyramidal cells, often near the calcium-storing spine apparatus. ${ }^{60}$ Postsynaptic, Gicoupled receptors can strengthen synaptic efficacy and enhance Delay cell firing by closing potassium channels ( $\mathrm{HCN}, \mathrm{KCNQ}$ ) whose open state is increased by CAMP-PKA signaling. ${ }^{35,50}$ As mGluR2/3 couple to $\mathrm{Gi} / \mathrm{Go}^{26}$ postsynaptic mGluR2/3 may reduce cAMP production, close cAMP/PKA-regulated potassium channels and enhance Delay cell firing. Consistent with this hypothesis, we found that low doses of mGluR2/3 agonists enhanced Delay cell firing, and that these effects were reversed by 8-Br-cAMP, which increases CAMP-PKA signaling. Although there are currently no available experimental techniques to allow us to definitively demonstrate that the enhancing effects of mGluR2/3 agonists arise from stimulation of postsynaptic receptors, the current data are consistent with this hypothesis.

In contrast, when doses of mGluR2/3 agonist were raised, there was a loss of Delay cell firing. This reduction in firing with higher doses is likely due to drug actions at receptors on the glutamatergic axon and/or perisynaptic astrocytes, where mGluR2/3 stimulation reduces glutamate release ${ }^{61-63}$ and increases glutamate uptake, ${ }^{28}$ respectively. These effects appear to be less responsive to drug than the potent, postsynaptic actions. The increased sensitivity of postsynaptic actions has been seen in previous studies as well, ${ }^{35}$ and may be due to the amplification produced by the positive feedback nature of cAMP-calcium signaling in spines within a recurrent excitatory circuitry. Thus, small changes in CAMP signaling in spines may be amplified to have large effects on physiology and behavior, whereas presynaptic actions may have a more linear relationship to dosage.

Apparent species differences in mGluR2/3 signaling in primates vs rodents

Previous physiological and biochemical studies in rodent PFC have found that mGluR2/3 stimulation reduces glutamate release and decreases excitation of the postsynaptic neuron. ${ }^{23,27,61,62}$ Although these findings are consistent with our high-dose APDC data, they are at odds with our findings that low doses of mGluR2/3 agonists increase neuronal firing. There are several possible explanations for the discrepancy between the rodent literature and the current data from primates. First, there may be true species differences, where rodent PFC has mostly presynaptic mGluR2/3, and very limited postsynaptic mGluR2/3 component. However, our infusion data in rodent PFC suggest that a very low dose of mGluR2/3 agonist can enhance working memory performance, similar to monkey. Thus, apparent species differences may actually be dose differences. Another possibility is that discrepancies arise from laminar differences: the primate dIPFC has a very large layer III and smaller layer V, whereas in rodent PFC, layer $\mathrm{V}$ is very extensive and layer II/III is sparse. ${ }^{24}$ Thus, assays of rat PFC generally sample from layer $\mathrm{V}$. Layer $\mathrm{V}$ cells in monkeys ('Response cells') are regulated differently than Delay cells, ${ }^{64,65}$ and more similarly to rodent layer $V$ neurons. ${ }^{32}$ For example, systemic administration of an NMDAR antagonist in primate increases the firing of Response cells, but uniformly reduces the firing of layer III Delay cells. Thus, the disproportionate sampling of layer $\mathrm{V}$ cells in rodents may generate the illusion of species differences. However, since it is these newly evolved layer III circuits that are of particular relevance to cognitive disorders in humans, these neurons should be a focus of mechanistic, translational studies.

Potential of mGluR2/3 agonist for treating cognitive disorders in humans

The findings of this work encourage the use of mGluR2/3 agonists for treating cognitive dysfunction in schizophrenia and aging. Studies of monkeys revealed that CAMP signaling becomes disinhibited in the aging dIPFC from reduced phosphodiesterase 4A expression, decreasing Delay cell firing and increasing tau phosphorylation. ${ }^{37,66}$ Studies of aging human dIPFC found reduced expression of mGluR2 $/ 3,{ }^{22}$ which may also contribute to disinhibited CAMP signaling with advancing age. As we observed that low doses of mGluR2/3 agonists improved working memory performance in aged monkeys with no obvious side effects, low doses of mGluR2/3 agonists may have therapeutic potential for treating age-related cognitive disorders.

The mGluR2/3 agonist, pomaglumetad methionil (LY2140023), has already been tested for antipsychotic actions in patients with schizophrenia, with mixed results. ${ }^{3-7}$ The doses tested in these studies ( 0.05-1.4 $\left.\mathrm{mg} \mathrm{kg}^{-1}\right)$ were higher compared with the APDC beneficial doses in the current study $\left(0.0001-0.01 \mathrm{mg} \mathrm{kg}^{-1}\right)$, suggesting that the dose may have been a factor in the mixed response. Consistent with this hypothesis, a new, exploratory meta-analysis of the clinical trials showed that the low dose, but not the high dose, of LY2140023 improved patients who were early in the disease. ${ }^{5}$ Our data suggest that these low, beneficial doses may have engaged postsynaptic receptors on dendritic spines, and that patients with more long-standing illness may have lost these spines and thus lost the substrate for the drug's therapeutic actions. It is hoped that future research can better isolate the beneficial effects of $\mathrm{mGluR2} / 3$ agonists at postsynaptic receptors, for example, by dissecting mGluR2 vs mGluR3 actions in primate dIPFC. Indeed, genetic variations in GRM3, but not GRM2, are associated with schizophrenia, and with altered dIPFC activation and lower performance during cognitive tasks. ${ }^{9,11,18}$ Studies using knockout animals also suggest that mGluR3 depletion leads to working memory impairments in mice. ${ }^{67,68}$ Interestingly, methylation of the promoter region of GRM2, which reduces mGluR2 expression, lowers the risk of schizophrenia. ${ }^{69}$ It is likely that mGluR2 and mGluR3 differ in their subcellular localization in dIPFC, for example, our preliminary data indicate that neuronal mGluR3 may be localized primarily at postsynaptic sites, whereas neuronal mGluR2 may have a presynaptic focus, and thus have distinct roles in working memory circuits. The ability to strengthen postsynaptic connections in layer III dIPFC working memory circuits, without reducing glutamate availability in these circuits, may produce a more robust enhancement of cognition that facilitates translation for human use.

\section{CONFLICT OF INTEREST}

The authors declare no conflict of interest.

\section{ACKNOWLEDGMENTS}

We thank L Ciavarella, S Johnson, T Sadlon, M Wilson and M Horn for their invaluable technical support. These studies were supported by PHS Grants R01AG043430-02 and R01MH100064-01A1 to AFTA, and donations to LEJ in memory of Percy Sanguinetti Arnsten and to CDP in memory of Elsie Louise Torrance Higgs, whose courage inspired this work.

\section{REFERENCES}

1 Li ML, Hu XQ, Li F, Gao WJ. Perspectives on the mGluR2/3 agonists as a therapeutic target for schizophrenia: still promising or a dead end? Prog Neuropsychopharmacol Biol Psychiatry 2015; 60: 66-76. 
2 Harrison PJ, Lyon L, Sartorius LJ, Burnet PW, Lane TA. The group II metabotropic glutamate receptor 3 (mGluR3, mGlu3, GRM3): expression, function and involvement in schizophrenia. J Psychopharmacol 2008; 22: 308-322.

3 Adams DH, Zhang L, Millen BA, Kinon BJ, Gomez JC. Pomaglumetad methionil (LY2140023 monohydrate) and aripiprazole in patients with schizophrenia: a phase 3, multicenter, double-blind comparison. Schizophr Res Treat 2014; 2014: 758212.

4 Downing AM, Kinon BJ, Millen BA, Zhang L, Liu L, Morozova MA et al. A doubleblind, placebo-controlled comparator study of LY2140023 monohydrate in patients with schizophrenia. BMC Psychiatry 2014; 14: 351.

5 Kinon BJ, Millen BA, Zhang L, McKinzie DL. Exploratory analysis for a targeted patient population responsive to the metabotropic glutamate $2 / 3$ receptor agonist pomaglumetad methionil in schizophrenia. Biol Psychiatry 2015; 78: 754-762.

6 Kinon BJ, Zhang L, Millen BA, Osuntokun OO, Williams JE, Kollack-Walker S et al. A multicenter, inpatient, phase 2, double-blind, placebo-controlled dose-ranging study of LY2140023 monohydrate in patients with DSM-IV schizophrenia. J Clin Psychopharmacol 2011; 31: 349-355.

7 Patil ST, Zhang L, Martenyi F, Lowe SL, Jackson KA, Andreev BV et al. Activation of mGlu2/3 receptors as a new approach to treat schizophrenia: a randomized phase 2 clinical trial. Nat Med 2007; 13: 1102-1107.

8 Bishop JR, Miller DD, Ellingrod VL, Holman T. Association between type-three metabotropic glutamate receptor gene (GRM3) variants and symptom presentation in treatment refractory schizophrenia. Hum Psychopharmacol 2011; 26: 28-34.

9 Chang M, Sun L, Liu X, Sun W, Ji M, Wang Z et al. Evaluation of relationship between GRM3 polymorphisms and cognitive function in schizophrenia of Han Chinese. Psychiatry Res 2015; 30: 1043-1046.

10 Corti C, Crepaldi L, Mion S, Roth AL, Xuereb JH, Ferraguti F. Altered dimerization of metabotropic glutamate receptor 3 in schizophrenia. Biol Psychiatry 2007; 62: 747-755.

11 Egan MF, Straub RE, Goldberg TE, Yakub I, Callicott JH, Hariri AR et al. Variation in GRM3 affects cognition, prefrontal glutamate, and risk for schizophrenia. Proc Natl Acad Sci USA 2004; 101: 12604-12609.

12 Fujii Y, Shibata H, Kikuta R, Makino C, Tani A, Hirata N et al. Positive associations of polymorphisms in the metabotropic glutamate receptor type 3 gene (GRM3) with schizophrenia. Psychiatric Genet 2003; 13: 71-76.

13 Kinoshita A, Takizawa R, Koike S, Satomura Y, Kawasaki S, Kawakubo Y et al. Effect of metabotropic glutamate receptor-3 variants on prefrontal brain activity in schizophrenia: an imaging genetics study using multi-channel near-infrared spectroscopy. Prog Neuropsychopharmacol Biol Psychiatry 2015; 62: 14-21.

14 Mössner R, Schuhmacher A, Schulze-Rauschenbach S, Kühn KU, Rujescu D, Rietschel $\mathrm{M}$ et al. Further evidence for a functional role of the glutamate receptor gene GRM3 in schizophrenia. Eur Neuropsychopharmacol 2008; 18: 768-772.

15 Mounce J, Luo L, Caprihan A, Liu J, Perrone-Bizzozero NI, Calhoun VD. Association of GRM3 polymorphism with white matter integrity in schizophrenia. Schizophr Res 2014; 155: 8-14.

16 O'Brien NL, Way MJ, Kandaswamy R, Fiorentino A, Sharp SI, Quadri G et al. The functional GRM3 Kozak sequence variant rs148754219 affects the risk of schizophrenia and alcohol dependence as well as bipolar disorder. Psychiatr Genet 2014; 24: $277-278$

17 Sartorius $\amalg$, Weinberger DR, Hyde TM, Harrison PJ, Kleinman JE, Lipska BK. Expression of a GRM3 splice variant is increased in the dorsolateral prefrontal cortex of individuals carrying a schizophrenia risk SNP. Neuropsychopharmacology 2008; 33: 2626-2634

18 Schizophrenia Working Group of the Psychiatric Genomics Consortium. Biological insights from 108 schizophrenia-associated genetic loci. Nature 2014; 511: 421-427.

19 Tan HY, Chen Q, Sust S, Buckholtz JW, Meyers JD, Egan MF et al. Epistasis between catechol-O-methyltransferase and type II metabotropic glutamate receptor 3 genes on working memory brain function. Proc Natl Acad Sci USA 2007; 104: 12536-12541.

20 Ghose S, Gleason KA, Potts BW, Lewis-Amezcua K, Tamminga CA. Differential expression of metabotropic glutamate receptors 2 and 3 in schizophrenia: a mechanism for antipsychotic drug action? Am J Psychiatry 2009; 166: 812-820.

21 Marenco S, Steele SU, Egan MF, Goldberg TE, Straub RE, Sharrief AZ et al. Effect of metabotropic glutamate receptor 3 genotype on $\mathrm{N}$-acetylaspartate measures in the dorsolateral prefrontal cortex. Am J Psychiatry 2006; 163: 740-742.

22 Colantuoni C, Hyde TM, Mitkus S, Joseph A, Sartorius L, Aguirre C et al. Age-related changes in the expression of schizophrenia susceptibility genes in the human prefrontal cortex. Brain Struct Funct 2008; 213: 255-271.

23 Moghaddam B, Adams BW. Reversal of phencyclidine effects by a group II metabotropic glutamate receptor agonist in rats. Science 1998; 281: 1349-1352.

24 DeFelipe J. The evolution of the brain, the human nature of cortical circuits, and intellectual creativity. Front Neuroanat 2011; 5: 29.

25 Elston GN. Cortex, cognition and the cell: new insights into the pyramidal neuron and prefrontal function. Cereb Cortex 2003; 13: 1124-1138.
26 Tanabe Y, Masu M, Ishii T, Shigemoto R, Nakanishi S. A family of metabotropic glutamate receptors. Neuron 1992; 8: 169-179.

27 Benneyworth MA, Xiang Z, Smith RL, Garcia EE, Conn PJ, Sanders-Bush E. A selective positive allosteric modulator of metabotropic glutamate receptor subtype 2 blocks a hallucinogenic drug model of psychosis. Mol Pharmacol 2007; 72: 477-484.

28 Aronica E, Gorter JA, ljlst-Keizers H, Rozemuller AJ, Yankaya B, Leenstra S et al. Expression and functional role of mGluR3 and mGluR5 in human astrocytes and glioma cells: opposite regulation of glutamate transporter proteins. Eur J Neurosci 2003; 17: 2106-2118

29 Tamaru Y, Nomura S, Mizuno N, Shigemoto R. Distribution of metabotropic glutamate receptor mGluR3 in the mouse CNS: differential location relative to pre- and postsynaptic sites. Neuroscience 2001; 106: 481-503.

30 Ster J, Mateos JM, Grewe BF, Coiret G, Corti C, Corsi M et al. Enhancement of CA3 hippocampal network activity by activation of group II metabotropic glutamate receptors. Proc Natl Acad Sci USA 2011; 108: 9993-9997.

31 Goldman-Rakic PS. Cellular basis of working memory. Neuron 1995; 14: 477-485.

32 Wang M, Yang Y, Wang CJ, Gamo NJ, Jin LE, Mazer JA et al. NMDA receptors subserve working memory persistent neuronal firing in dorsolateral prefrontal cortex. Neuron 2013; 77: 736-749.

33 Arnsten AF, Wang MJ, Paspalas CD. Neuromodulation of thought: flexibilities and vulnerabilities in prefrontal cortical network synapses. Neuron 2012; 76: 223-239.

34 Arnsten AF, Jin LE. Guanfacine for the treatment of cognitive disorders: a century of discoveries at Yale. Yale J Biol Med 2012; 85: 45-58.

35 Wang M, Ramos B, Paspalas C, Shu Y, Simen A, Duque et al. Alpha2Aadrenoceptor stimulation strengthens working memory networks by inhibiting CAMP-HCN channel signaling in prefrontal cortex. Cell 2007; 129: 397-410.

36 Morrison JH, Baxter MG. The ageing cortical synapse: hallmarks and implications for cognitive decline. Nat Rev Neurosci 2012; 13: 240-250.

37 Wang $M$, Gamo NJ, Yang $Y$, Jin LE, Wang XJ, Laubach $M$ et al. Neuronal basis of age-related working memory decline. Nature 2011; 476: 210-213.

38 Perlstein WM, Carter CS, Noll DC, Cohen JD. Relation of prefrontal cortex dysfunction to working memory and symptoms in schizophrenia. Am J Psychiatry 2001; 158: 1105-1113.

39 Selemon LD, Goldman-Rakic PS. The reduced neuropil hypothesis: a circuit based model of schizophrenia. Biol Psychiatry 1999; 45: 17-25.

40 Selemon LD, Rajkowska G, Goldman-Rakic PS. Abnormally high neuronal density in the schizophrenic cortex. A morphometric analysis of prefrontal area 9 and occipital area 17. Archiv Gen Psychiatry 1995; 52: 805-818, discussion 819-820.

41 Glantz LA, Lewis DA. Decreased dendritic spine density on prefrontal cortical pyramidal neurons in schizophrenia. Arch Gen Psychiatry 2000; 57: 65-73.

42 Lewis DA, Gonzalez-Burgos G. Pathophysiologically based treatment interventions in schizophrenia. Nat Med 2006; 12: 1016-1022.

43 Krystal JH, D'Souza DC, Mathalon D, Perry E, Belger A, Hoffman R. NMDA receptor antagonist effects, cortical glutamatergic function, and schizophrenia: toward a paradigm shift in medication development. Psychopharmacology 2003; 169: 215-233.

44 Driesen NR, McCarthy G, Bhagwagar Z, Bloch M, Calhoun V, D'Souza DC et al. Relationship of resting brain hyperconnectivity and schizophrenia-like symptoms produced by the NMDA receptor antagonist ketamine in humans. Mol Psychiatry 2013; 18: 1199-1204

45 Gamo NJ, Duque A, Paspalas CD, Kata A, Fine R, Boven L et al. Role of disrupted in schizophrenia 1 (DISC1) in stress-induced prefrontal cognitive dysfunction. Trans/ Psychiatry 2013; 3: e328.

46 El-Hassar L, Simen AA, Duque A, Patel KD, Kaczmarek LK, Arnsten AF et al. Disrupted in schizophrenia 1 modulates medial prefrontal cortex pyramidal neuron activity through CAMP regulation of transient receptor potential $C$ and smallconductance $\mathrm{K}^{+}$channels. Biol Psychiatry 2014; 76: 476-485.

47 Millar JK, Wilson-Annan JC, Anderson S, Christie S, Taylor MS, Semple CA et al. Disruption of two novel genes by a translocation co-segregating with schizophrenia. Hum Mol Genet 2000; 9: 1415-1423.

48 Deng X, Takaki H, Wang L, Kuroki T, Nakahara T, Hashimoto K et al. Positive association of phencyclidine-responsive genes, PDE4A and PLAT, with schizophrenia. Am J Med Genet B 2011; 156B: 850-858.

49 Hackler EA, Byun NE, Jones CK, Williams JM, Baheza R, Sengupta $S$ et al. Selective potentiation of the metabotropic glutamate receptor subtype 2 blocks phencyclidine-induced hyperlocomotion and brain activation. Neuroscience 2010; 168: $209-218$.

50 Paspalas CD, Wang M, Arnsten AF. Constellation of HCN channels and CAMP regulating proteins in dendritic spines of the primate prefrontal cortex: potential substrate for working memory deficits in schizophrenia. Cereb Cortex 2013; 23: 1643-1654.

51 Yang Y, Paspalas CD, Jin LE, Picciotto MR, Arnsten AF, Wang M. Nicotinic alpha7 receptors enhance NMDA cognitive circuits in dorsolateral prefrontal cortex. Proc Natl Acad Sci USA 2013; 110: 12078-12083. 
52 Arnsten AF, Goldman-Rakic PS. Noise stress impairs prefrontal cortical cognitive function in monkeys: evidence for a hyperdopaminergic mechanism. Archiv Gen Psychiatry 1998; 55: 362-368.

53 Gamo NJ, Wang M, Arnsten AF. Methylphenidate and atomoxetine enhance prefrontal function through alpha2-adrenergic and dopamine D1 receptors. $J \mathrm{Am}$ Acad Child Adolesc Psychiatry 2010; 49: 1011-1023.

54 Gamo NJ, Lur G, Higley MJ, Wang M, Paspalas CD, Vijayraghavan S et al. Stress impairs prefrontal cortical function via D1 dopamine receptor interactions with hyperpolarization-activated cyclic nucleotide-gated channels. Biol Psychiatry 2015; 78: 860-870.

55 Seeman P, Guan HC. Glutamate agonists for treating schizophrenia have affinity for dopamine D2High and D3 receptors. Synapse 2009; 63: 705-709.

56 Fell MJ, Perry KW, Falcone JF, Johnson BG, Barth VN, Rash KS et al. In vitro and in vivo evidence for a lack of interaction with dopamine D2 receptors by the metabotropic glutamate $2 / 3$ receptor agonists 1 S,2 S,5 R,6 S-2-aminobicyclo [3.1.0]hexane-2,6-bicaroxylate monohydrate (LY354740) and (-)-2-oxa-4-aminobicyclo[3.1.0] hexane-4,6-dicarboxylic acid (LY379268). J Pharmacol Exp Ther 2009; 331: 1126-1136.

57 Zysk JR, Widzowski D, Sygowski LA, Knappenberger KS, Spear N, Elmore CS et al. Absence of direct effects on the dopamine D2 receptor by mGluR2/3-selective receptor agonists LY 354,740 and LY 379,268. Synapse 2011; 65: 64-68.

58 Krystal JH, Karper LP, Seibyl JP, Freeman GK, Delaney R, Bremner JD et al. Subanesthetic effects of the noncompetitive NMDA antagonist, ketamine, in humans. Psychotomimetic, perceptual, cognitive, and neuroendocrine responses. Archiv Gen Psychiatry 1994; 51: 199-214.

59 Arion D, Corradi JP, Tang S, Datta D, Boothe F, He et al. Distinctive transcriptome alterations of prefrontal pyramidal neurons in schizophrenia and schizoaffective disorder. Mol Psychiatry 2015; 20: 1397-1405.

60 Sabatini BL, Oertner TG, Svoboda K. The life cycle of $\mathrm{Ca}(2+)$ ions in dendritic spines. Neuron 2002; 33: 439-452.

61 Kamiya H, Shinozaki H, Yamamoto C. Activation of metabotropic glutamate receptor type $2 / 3$ suppresses transmission at rat hippocampal mossy fibre synapses. J Physiol 1996; 493, Pt 2 447-455.

62 Wang S, Chen X, Kurada L, Huang Z, Lei S. Activation of group II metabotropic glutamate receptors inhibits glutamatergic transmission in the rat entorhinal cortex via reduction of glutamate release probability. Cereb Cortex 2012; 22: 584-594.

63 Rohde J, Kirschstein T, Wilkars W, Müller L, Tokay T, Porath K et al. Upregulation of presynaptic mGluR2, but not mGluR3 in the epileptic medial perforant path. Neuropharmacology 2012; 62: 1867-1873.

64 Wang M, Vijayraghavan S, Goldman-Rakic PS. Selective D2 receptor actions on the functional circuitry of working memory. Science 2004; 303: 853-856.

65 Funahashi S, Bruce CJ, Goldman-Rakic PS. Neuronal activity related to saccadic eye movements in the monkey's dorsolateral prefrontal cortex. I Neurophysiol 1991; 65: 1464-1483.

66 Carlyle BC, Nairn AC, Wang M, Yang Y, Jin LE, Simen AA et al. CAMP-PKA phosphorylation of tau confers risk for degeneration in aging association cortex. Proc Natl Acad Sci USA 2014; 111: 5036-5041.

67 Fujioka R, Nii T, Iwaki A, Shibata A, Ito I, Kitaichi K et al. Comprehensive behavioral study of mGluR3 knockout mice: implication in schizophrenia related endophenotypes. Mol Brain 2014; 7: 31.

68 Lainiola M, Procaccini C, Linden AM. mGluR3 knockout mice show a working memory defect and an enhanced response to MK-801 in the T- and Y-maze cognitive tests. Behav Brain Res 2014; 266: 94-103.

69 Kordi-Tamandani DM, Dahmardeh N, Torkamanzehi A. Evaluation of hypermethylation and expression pattern of GMR2, GMR5, GMR8, and GRIA3 in patients with schizophrenia. Gene 2013; 515: 163-166.

This work is licensed under a Creative Commons AttributionNonCommercial-NoDerivs 4.0 International License. The images or other third party material in this article are included in the article's Creative Commons
license, unless indicated otherwise in the credit line; if the material is not included under the Creative Commons license, users will need to obtain permission from the license holder to reproduce the material. To view a copy of this license, visit http:// creativecommons.org/licenses/by-nc-nd/4.0/

(c) The Author(s) 2017

Supplementary Information accompanies the paper on the Molecular Psychiatry website (http://www.nature.com/mp) 